\title{
Assessment of Heavy Metals on Occupationally Exposed Workers from Hair Analysis
}

\author{
E. Damastuti ${ }^{\star}$ N. Adventini, W.Y.N. Syahfitri, S. Kurniawati, \\ D.D. Lestiani and M. Santoso \\ Center for Applied Nuclear Science and Technology, National Nuclear Energy Agency, \\ Jl. Tamansari 71, Bandung 40132, Indonesia
}

\section{ARTICLE INFO}

\section{Article history:}

Received 2 November 2015

Received in revised form 10 May 2017

Accepted 22 May 2017

\section{Keywords:}

Human hair

Occupational exposure

Heavy metals

Nuclear analytical technique

Workshop workers

Traffic services officers

\begin{abstract}
A B S T R A C T
The use of human hair as a tool in assessing changes and abnormalities in human bodies has been increasing for last decades since it may reflect the health status or environmental condition of habitation or working place of individuals as well as population groups. Compared to other body tissue or fluids, hair provides an ease of elemental analysis especially in reflecting the long-term exposure. This research was conducted to determine the elemental content especially heavy metals, since they are bioaccumulated in human body organs and impact human health, in hair of workshop workers and traffic services officers as exposed groups and its comparison with control group and references data for assessing of occupational exposure. Thirty-five automotive workshop workers and 32 traffic services officers' hair specimens were collected in Bandung, while hair specimens of the control group were collected from 43 healthy individuals. The elemental concentrations in hair specimen were analyzed using neutron activation analysis (NAA) for mercury and chromium, and atomic absorption spectrometry (AAS) for lead and arsenic. The accuracy of the method was evaluated using GBW 07601 human hair certified reference material (CRM) and it was found to give good results in accordance with the certificate values. It was found that chromium, lead, and arsenic hair concentration in exposed groups $(0.88,10.7$, and $0.051 \mathrm{mg} / \mathrm{kg}$, respectively) were higher than in control group $(0.27,4.52$, and $0.045 \mathrm{mg} / \mathrm{kg}$, respectively), while mercury hair concentration of traffic services officers were higher than control group but mercury hair concentration of automotive workshop workers were lower than in control group $(1.41 \mathrm{mg} / \mathrm{kg})$. The t-test statistical results shown that mercury concentrations in one exposed group did not differ significantly from the control, but other exposed groups showed otherwise. The level of mercury in hair is strongly attributed not only to environmental exposure, but also to lifestyle and dietary habits, while t-test statistical results of chromium and lead differ significantly with $\mathrm{p}$ value $<0.05$. These results indicate that heavy metal hair concentrations were well quantified to show the abnormalities of elemental concentration in human hair for evaluating the occupational exposure.
\end{abstract}

(C) 2017 Atom Indonesia. All rights reserved

\section{INTRODUCTION}

The hair is a bioindicator that may reflect human health status. The use of human hair as an bioindicator in assessing changes and abnormalities in human bodies has gained great attention in the last several decades for occupational exposure evaluation, criminal investigation, or investigation

\footnotetext{
${ }^{*}$ Corresponding author.

E-mail address: endah_dt@batan.go.id

DOI: https://doi.org/10.17146/aij.2017.772
}

of the effects of environmental conditions on the health status of individuals and population groups $[1,2]$. The abnormalities of elemental concentration in human hair generally need to be considered for studying the occupational exposure [3-5].

As the hair grows by approximately $1 \mathrm{~cm} \mathrm{a}$ month, nutrients and toxic elements are deposited from the blood stream into the hair follicles and hair shafts; therefore, the concentration of these elements in hair is proportional to their concentration in the blood at the time of hair 
formation [2,6-9]. Those elements, when they are deposited in hair follicle, will be sequestered in protein matrices through binding with sulfur atoms in cysteine or sulfhydryl groups in other amino acids and experienced hardening processes, keratinocytes, while the hair growth then accumulated in the hair [7-10].

For elemental analysis, compared to other human tissues or fluids, such as urine or blood, collecting samples of human hair is easier and painless. Transporting and storing the samples are also easier. Furthermore, hairs also provide a record of past and current trace element levels since it has the ability to accumulate the elements entering the body [9-11].

Metallic elements are divided into two groups: essential elements such as iron and calcium, and toxic elements such as mercury, lead, and arsenic [12]. Ullah [13] defined heavy metals as the generic term for metallic elements which have density five times greater than density of water, but as stated by Duffus [14], the term "heavy metals" has been given wide range of meaning by many authors, and it has never been defined by any authoritative body such as IUPAC. However, "heavy metals" is often used as a group name for metals and metalloids that have been associated with contamination and potential toxicity or ecotoxicity. From 92 naturally occurring elements, approximately 30 metals and metalloids are potentially toxic to humans. The most found heavy metals that are extremely toxic even in a small amounts are lead, cadmium, chromium, mercury, and arsenic [15]. Heavy metals are dangerous because they are bioaccumulated in human body organs such as liver, lung, kidney, or bone, which impact human health [2,15]. It is known that heavy metal exposure can occur from industrial effluents, environmental contamination, occupational exposure, volcanic gasses, and emissions by coal-fired power plants or industries.

Some of elemental characterization of human hair in Indonesia had been carried out by Ponzetta et al. that analyzed the trace elements in the Irianese (Papuans) to investigate the physical characteristics among them and by Foo et al. who analyzed the elements in the hairs of the people from Batam [16,17]. The abnormalities of chromium concentration in human hair related to androgenic alopecia had also been investigated by Saputri et al. [18]. Unfortunately, however, the use of hair analysis in assessing occupational exposure, as well as in reflecting health status, is still limited. On the previous research, we have done the elemental hair characterization of officers from DLLAJR (Indonesian Traffic and Road Transportation Services - Dinas Lalu Lintas dan Angkutan Jalan Raya in Indonesian) as a preliminary study of the ability of hair analysis to assess occupational exposure. The results showed some differences between the exposed officers and the control group [19].

The limitations of the data in the previous research encourage us to conduct this research by adding the number of control samples and the exposed groups of automotive workshop workers in order to further ensure the ability of the hair analysis to assess the occupational exposure that is now focused on heavy metal elements. The term "heavy metals" as used in this article refers to lead, mercury, arsenic, and chromium. Lead, mercury, and arsenic are widely dispersed in environment and generally considered as the most toxic to human and animals [13]. Along with chromium, they are elements that have been associated with vehicle emissions as well repair and manufacturing activities such as painting and welding. The elemental characterization of human hair was carried out by neutron activation analysis (NAA) and atomic absorption spectroscopy (AAS), and to ensure the quality and reliability of the analytical results, certified reference materials (CRM) with similar matrices were used for quality assurance purposes.

\section{EXPERIMENTAL METHODS}

\section{Hair sampling and preparation}

Hair samples were collected from 35 workers from an automotive workshop in Jl. Gatot Subroto, Bandung and 32 officers of DLLAJR Bandung City (hereinafter called traffic services officers) as heavy-metal exposed groups, while 43 healthy individuals served as a control group. The control group members were recommended by physicians at the Center for Applied Nuclear Science and Technology and were employees of this institution who were not affected by occupational exposure. All of the volunteers involved were informed about the purpose of this study. They were invited to follow medical examination after filling information forms about their age, gender, working period, lifestyle habits (e.g., eating and smoking), health record, and job categories. Collection of human hair specimen was performed by cutting the hair strand close to the scalp in the occipital portion of the head as described in Fig. 1 [20-23]. 


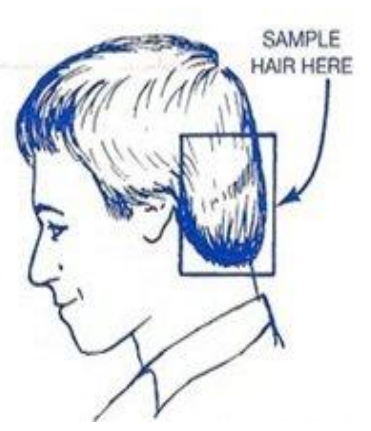

Fig. 1. Hair collection location.

This procedure describes several criteria that must be met in determining of hair specimen that gives reliably value of hair specimen analysis with good reproducibility. Approximately $5 \mathrm{~g}$ of hair was cut with stainless steel scissor. The collected hair specimen was cut into small pieces $(2-5 \mathrm{~mm})$ to obtain representative homogenous samples. Then, those pieces were wrapped with envelopes. To remove dust and other external contaminants, the hair sample was washed four times under continuous stirring in a sequence of acetone and purified water [23-25]. After being washed, each sample was dried at $40{ }^{\circ} \mathrm{C}$ in an oven for about 48 hours.

\section{Neutron activation analysis (NAA) procedure}

Neutron activation analysis is a method for qualitative and quantitative determination of elements based on the measurement of the characteristic radiation from radionuclides formed by neutron irradiation of the material. The elemental concentrations are calculated by comparative method. In this experiment, about $0.025 \mathrm{~g}$ of hair samples and $0.025 \mathrm{~g}$ of GBW 07601 human hair CRM were weighed in $0.273 \mathrm{~mL}$ polyethylene vial. The comparative standard was prepared by gradually pipetting the mixed standard solution of mercury and chromium to obtain the final concentrations of 0.1 and $0.2 \mu \mathrm{g}$ in $100 \mu \mathrm{L}$ solution, respectively, at $0.273 \mathrm{~mL}$ polyethylene vial and then were dried at $60^{\circ} \mathrm{C}$.

Then, the hair samples, human hair CRM, and standard were irradiated in the G. A. Siwabessy multipurpose nuclear reactor, Serpong, for two hours with a thermal neutron flux of $\sim 10^{13} \mathrm{n} /\left(\mathrm{cm}^{2} \mathrm{~s}\right)$. After a two-week decay time, the irradiated samples, human hair CRM, and standards were measured for 35000 seconds using gamma spectrometer with HPGe detector from Canberra. The resolution (FWHM) of the system was $1.90 \mathrm{keV}$ for the $1332 \mathrm{keV}$ gamma ray of ${ }^{60} \mathrm{Co}$. The radionuclides measured were identified according to their halflives and gamma ray energies. The radionuclides determined in hair analyses were ${ }^{51} \mathrm{Cr}$ at $320.08 \mathrm{keV}$ and ${ }^{203} \mathrm{Hg}$ at $279.19 \mathrm{keV}$. The gamma spectrum of the hair samples can be seen in Fig. 2. Gamma spectrum analysis was performed by Genie 2000 software.

\section{Atomic absorption spectrometry (AAS) procedure}

Atomic absorption spectrometry was used to determine lead and arsenic concentrations that cannot be quantified well by NAA. Approximately $0.5 \mathrm{~g}$ of hair samples was dissolved in a mixture of concentrated nitric acid $65 \%$ suprapure and demineralized water in the ratio of $3: 1$ by microwave analysis (ETHOS 1 Microwave Digestion, Milestone). After being dissolved,

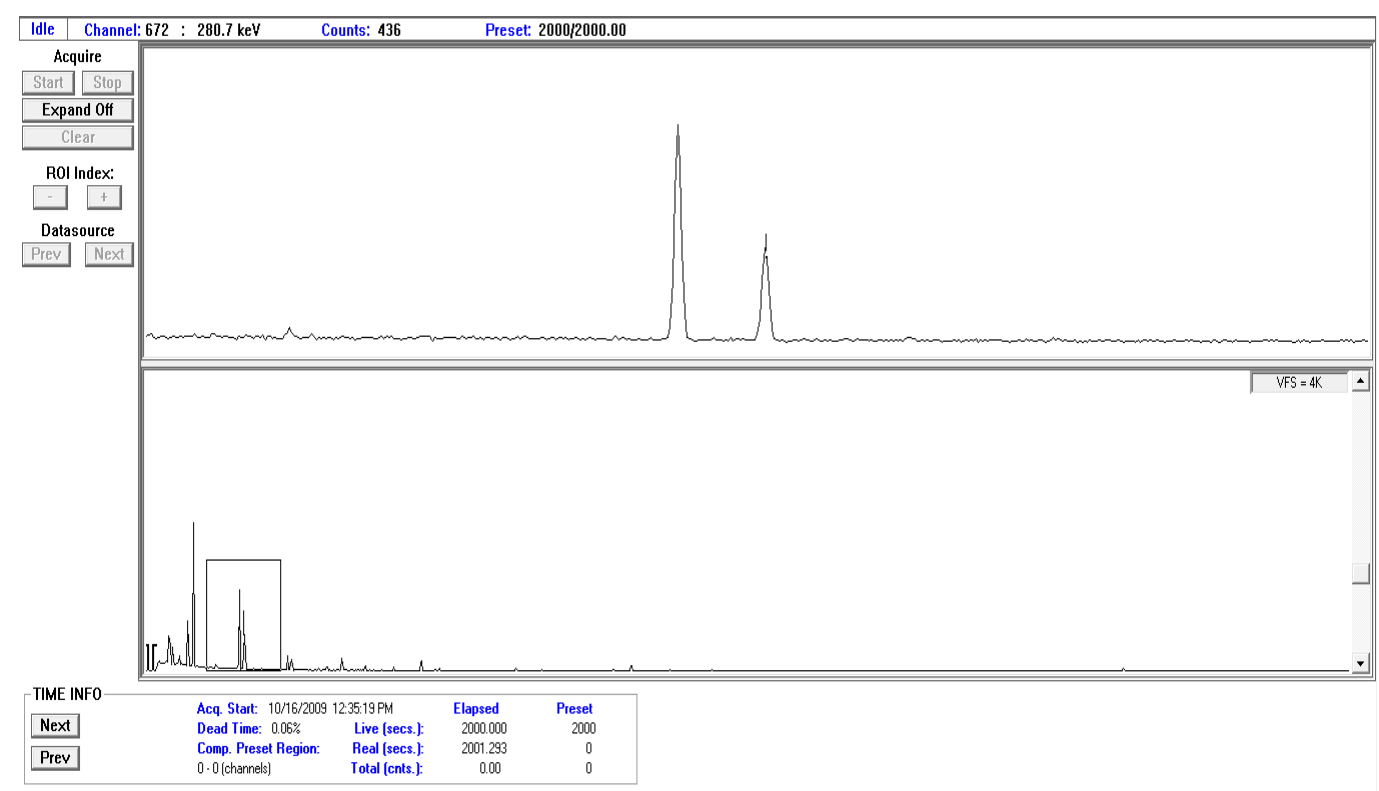

Fig. 2. Gamma ray spectrum of hair sample. 
arsenic and lead concentrations were determined using atomic absorption spectrometry (GBC 932 AA). Lead and arsenic concentrations were determined by means of a flame and hydride generation method, respectively. The same certified reference material as mentioned above was used to evaluate the accuracy and precision of lead and arsenic in human hair samples.

\section{RESULTS AND DISCUSSION}

From the information forms that have been filled by the volunteers, it can be concluded that as many as 35 automotive workshop workers were in the age group of 20-55 years. They consisted of 31 males and four females with four job categories, i.e., 18 auto mechanics, two painters, four drivers, and 11 administrative staffers. Their working period ranged from 1-30 years and as much as $60 \%$ of the automotive workshop workers are smokers. The 32 DLLAJR officers consisted of 31 males and one female with an age range of 17-56 years. They are 15 field officers, two honorary workers, five vehicle emission testing officers, and nine administrative staffers. Similarly with automotive workshop workers, $60 \%$ of the DLLAJR officers were smokers.

The quality control implementation was conducted by elemental analysis of the GBW 07601 human hair CRM which has a similar matrix with the samples, using the same analytical methods as the samples in order to assure the quality of the analytical results. The analytical results of elements in the CRM were shown in Table 1. The results showed good agreement with its certificate values with percentage bias of less than $10 \%$.

Table 1. The quality control results using GBW human hair CRM

\begin{tabular}{lcccc}
\hline Element & $\begin{array}{c}\text { Results } \\
(\mathrm{mg} / \mathrm{kg})\end{array}$ & $\begin{array}{c}\text { Cert. value } \\
(\mathrm{mg} / \mathrm{kg})\end{array}$ & $\%$ bias & Method \\
\hline Mercury & 0.37 & $0.36 \pm 0.08$ & 1 & NAA \\
Chromium & 0.37 & $0.37 \pm 0.06$ & 1 & NAA \\
Lead & 8.3 & $8.8 \pm 1.1$ & 6 & AAS \\
Arsenic & 0.30 & $0.28 \pm 0.05$ & 5 & AAS \\
\hline
\end{tabular}

The results of the comparison of geomean concentration between exposed groups and control group can be seen in Table 2. It is shown that lead and chromium concentrations on the exposed groups were higher than those on the control group, while mercury does not show a similar tendency. The variation of mercury concentration was caused more by life style and history of medication [26]. It is also shown that the geomean hair arsenic concentration of these workshop workers $(0.051 \mathrm{mg} / \mathrm{kg})$ was slightly higher than the control reference value $(0.045 \mathrm{mg} / \mathrm{kg})$ [9].

The difference of the geomean of each elemental concentration was examined statistically to determine its significance. The one-tailed Student's t-test assuming unequal variances were used to examine the statistical differences of the means between groups. The results of statistical tests are also shown in Table 2.

From Table 2, it can be seen that lead was detected in higher concentrations in the exposed group than in the control group. As the concentration of lead was twice as high, results from the one-tailed Student's t-test showed that there is significant difference with $\mathrm{p}$-value $<0.05$. Lead concentration in hair specimen of exposed group were in the range $2.5-44.7 \mathrm{mg} / \mathrm{kg}$ as presented in Fig. 3.

Some of the lead concentrations in hair samples of exposed group were below the detection limit of the flame-AAS method, while others that were well quantified were almost all higher than the $4.52 \mathrm{mg} / \mathrm{kg}$ geomean of the lead concentrations of the control group. These results emphasize that there were trends of lead exposure on the work area. The highest lead concentration was in hair specimen of a car painter (samples ID 7). Lead is one of the heavy metals contained in commonly-used raw materials in paint manufacturing as pigments or preservatives [27]. In his study, Awodele found that lead concentration in the urine of paint factory workers was twice as high as found in non-factory workers [27]. Lead is also one of the most-used nonferrous metals in the manufacture of metal products, chemical, batteries, and various other items [28]. Human hair usually contains less than $5 \mathrm{mg} / \mathrm{kg}$ of lead, and high exposure is indicated by lead concentrations of above $25 \mathrm{mg} / \mathrm{kg}$ [28]. Therefore, from this statement, it can be concluded that the exposed groups studied here had not suffered from high occupational lead exposure. However, as can be seen in Fig. 3, more than about $30 \%$ of automotive workshop workers as well as traffic services officers have lead concentration more than twice as great as the control group, showing a tendency of high environmental lead exposure. Special attention should be given to those who have more than $20 \mathrm{mg} / \mathrm{kg}$ of $\mathrm{Pb}$ since they have high risk to be exposed of this pollutant related to their job descriptions as painters, auto mechanics, field officers, and vehicle emission testing officers.

The mercury concentration of traffic services officers was three times as high as the control group while the mercury concentration of automotive 
Table 2. The geomean concentration of lead, mercury and chromium in control group, traffic services officers, and automotive workshop workers, and its ratios to the control group and $p$-values with significance $(p=0.05)$.

\begin{tabular}{|c|c|c|c|c|c|c|c|}
\hline \multirow[b]{2}{*}{ Elements } & \multirow{2}{*}{$\begin{array}{c}\text { Geomean Conc. } \\
\text { Control }(\mathrm{n}=43) \\
(\mathrm{mg} / \mathrm{kg})\end{array}$} & \multicolumn{3}{|c|}{ Traffic services officers $(n=32)$} & \multicolumn{3}{|c|}{ Automotive workshop workers $(n=35)$} \\
\hline & & $\begin{array}{l}\text { Geomean Conc. } \\
(\mathrm{mg} / \mathrm{kg})\end{array}$ & Ratio & p-value & $\begin{array}{l}\text { Geomean Conc. } \\
(\mathrm{mg} / \mathrm{kg})\end{array}$ & Ratio & p-value \\
\hline Lead & $4.52 \pm 0.32$ & $7.12 \pm 0.86$ & 1.58 & 0.023 & $10.9 \pm 0.53$ & 2.41 & 0.012 \\
\hline Mercury & $1.41 \pm 0.10$ & $4.72 \pm 0.18$ & 3.36 & 0.002 & $0.63 \pm 0.03$ & 0.45 & 0.191 \\
\hline Chromium & $0.27 \pm 0.13$ & $0.87 \pm 0.29$ & 3.23 & 0.000 & $0.50 \pm 0.11$ & 1.85 & 0.005 \\
\hline Arsenic & $0.045^{*}$ & N.A & - & - & $0.051 \pm 0.002$ & 1.16 & - \\
\hline
\end{tabular}

*Reference value [9]

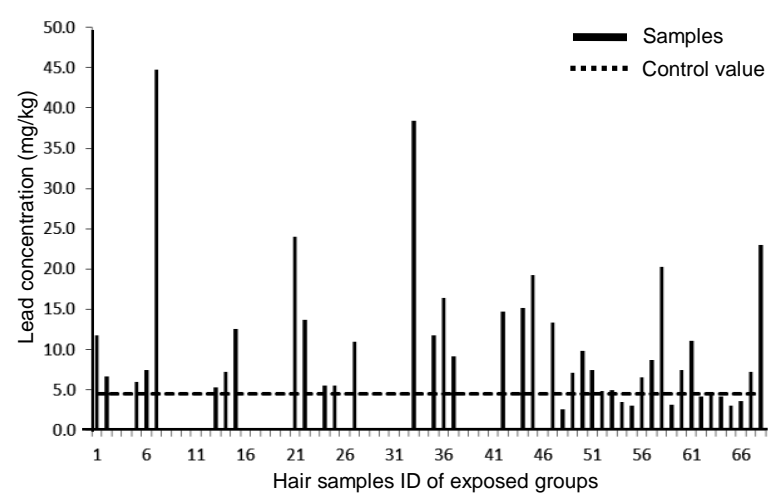

Fig. 3. Lead hair concentrations of automotive workshop workers (1-35) and traffic services officers $(36,67)$.

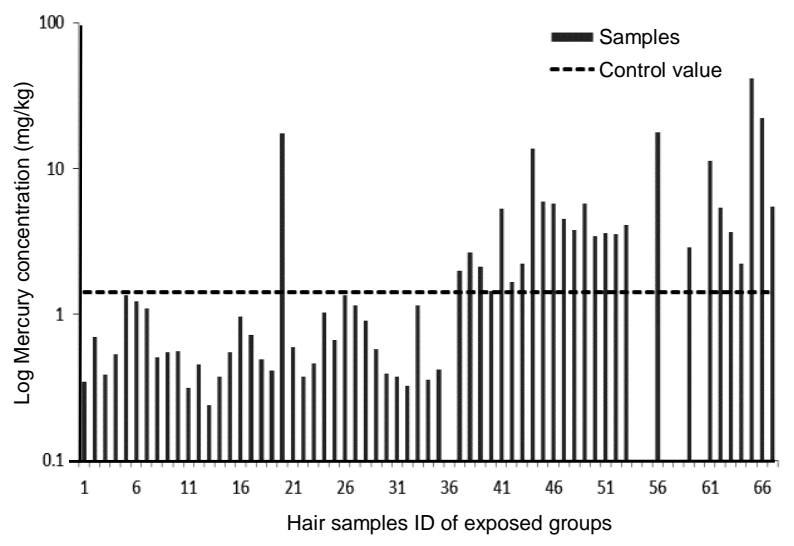

Fig. 4. Mercury hair concentrations of automotive workshop workers (1-35) and traffic services officers $(36,67)$.

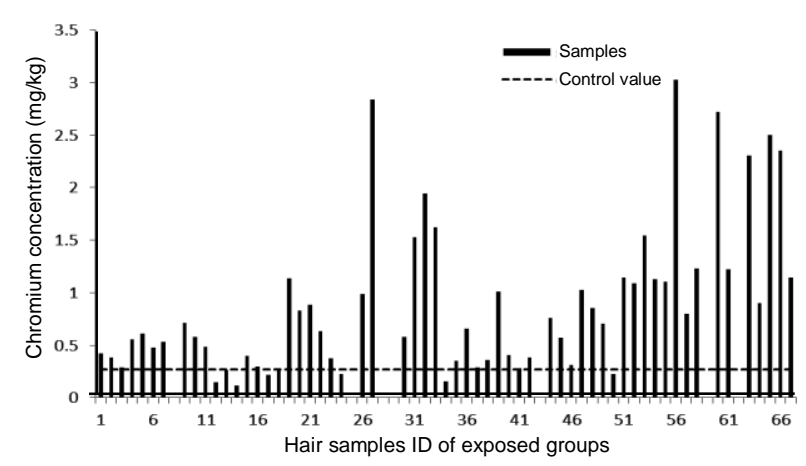

Fig. 5. Chromium hair concentrations of automotive workshop workers (1-35) and traffic services officers $(36,67)$. workshop workers were lower than the control group, as can be seen in Table 2. However, the differences between control group with exposed group of automotive workshop workers was not significant according to statistical test results, while with traffic services officers it was the contrary. Mercury concentration in the hair of automotive workshop workers were in the range of $0.24-17.5 \mathrm{mg} / \mathrm{kg}$, while in traffic services officers they were in the range of $1.44-41.4 \mathrm{mg} / \mathrm{kg}$ as presented in Fig. 4. Figure 4 shows that the variances of mercury concentrations in hair specimens were quite large in both exposed groups and also control group that was also described in Table 2. These led to the highest of mercury concentration being unable to be correlated to particular kind of work since the presence of mercury in hair specimen is strongly attributed to environmental exposure, lifestyle, and dietary habits [29,30]. Dietary habits, especially fish consumption, is considered to be the main source of mercury exposure particularly in the form of methyl mercury [31,32]. The occupational exposure of mercury should be further studied by giving more attention to more details associated with consumption patterns, lifestyles, living environment, and medical status.

Unlike with mercury, chromium concentration in the hair of both exposed groups was significantly different from the control group. The hair chromium concentration of automotive workshop workers were in the range of 0.11 $2.84 \mathrm{mg} / \mathrm{kg}$, while in traffic services officers they were in the range of $0.22-3.02 \mathrm{mg} / \mathrm{kg}$, as presented in Fig. 5.

As can be seen in Fig. 5, almost all of chromium concentrations in the hairs of both exposed groups were higher than among the control value. This shows similar trends with results obtain by Ramakhrisna et al. [33]. Chromium, along with other heavy metals $(\mathrm{Pb}, \mathrm{Cd}, \mathrm{Cu}, \mathrm{Ni}$ and $\mathrm{Zn})$, came from vehicle emission due to fuel combustion; it is also commonly found in oil residues and is released from metal corrosions $[33,34]$. 
One of main task of traffic services officers is testing the emission of vehicles. Therefore, it can be strongly suspected that the source of chromium exposure was vehicle emission. This is apparently the case with automotive workshop workers as well. Their work is strongly related to the fuel combustion of vehicle and oil residues as well. However, these were not the only source of chromium exposure and other heavy metals observed. The questionnaire results showed that more than $50 \%$ of both exposed groups were smokers. According to Yong-Liang Yu [35], the chromium content of cigarette filters was $165 \pm 11 \mathrm{ng}$ per cigarette, while in the tobacco blend it was $126.7 \pm 3.7 \mathrm{ng}$ per cigarette, and it can accumulate in human tissues including the hair. Lead exposure in hair were also partly contributed by cigarettes. According Hong et al., smokers tend to have more heavy metals than nonsmokers [29]. Therefore, it can be concluded that chromium, lead, and mercury exposure occurred in exposed groups and it derived from fuel combustion/vehicle emission and smoking habit as well.

Arsenic is abundant on the earth, but exposure to arsenic has adverse health effects. Acute arsenic toxicity affects many organ systems including the gastrointestinal, dermal, nervous, hematopoietic, and cardiovascular systems. Long-term exposure to non-lethal doses of arsenic has been found to induce peripheral neuropathy, anemia, cardiac and peripheral vascular disease, hyperkeratosis, and hyperpigmentation of the skin. Inorganic arsenic induces cancer of the skin, liver, and lung [36]. Arsenic compounds may be absorbed after ingestion, inhalation, or skin contact and are excreted in the urine. The arsenic concentration in hair samples of automotive workshop workers were in the range $0.02-0.152 \mathrm{mg} / \mathrm{kg}$ with a geomean of $0.05 \mathrm{mg} / \mathrm{kg}$ as presented in Fig. 6 .

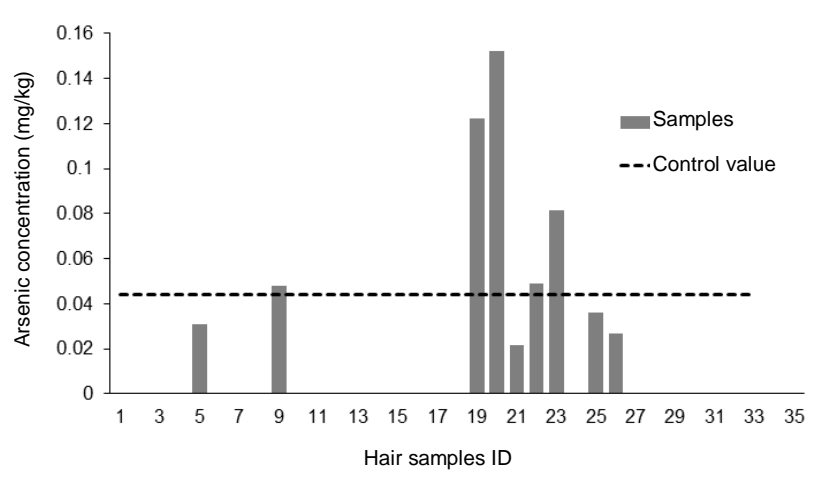

Fig. 6. Arsenic hair concentration of exposed group.

Some of the arsenic concentration in hair samples of exposed group were below the detection limit of the Hydride Generation-AAS method. The other values that were well quantified were then compared with control values adopted from normal ranges or tolerated limit values $(0.045 \mathrm{mg} / \mathrm{kg})$ in human hair specimen obtained by Yuxue Pan [9]. It can be seen that some have higher arsenic concentrations than the control value while other have lower values than the control value. Some of the workers that had high arsenic concentration are one painter (samples ID 19) $(0.122 \mathrm{mg} / \mathrm{kg})$ and two auto mechanics (samples ID 23 and 20) $(0.079 \mathrm{mg} / \mathrm{kg}$ and $0.152 \mathrm{mg} / \mathrm{kg}$, respectively).

Arsenic has been used as a pigment in paint and as an anti-fouling ingredient. Siew Lai Huang studied the particle size distribution and concentration of metallic elements of solvent- and water-based paint dust from collected bulk dust and found that the mean concentration of arsenic in solvent-based paint dust was $100 \pm 0.020 \mathrm{mg} / \mathrm{kg}$ while the mean concentrations of arsenic in waterbased paint dust was $20.65 \pm 6.11 \mathrm{mg} / \mathrm{kg}$ [37]. Awodele $e t$ al. found that arsenic concentration in urine sample of paint factory workers was 20 times as high as that found in non-factory workers [27]. Lubricant oils are used in a variety of applications. In an automobile workshop, lubricant oils are mainly used for automobile engines and brakes. The use of these lubricant oils produced used lubricant oils which contain dirt, metal scrapings, water, or chemicals. Used lubricant oil and its effect on the environment has been studied by Faiza Iljas who found that the average level of arsenic in the used lubricant were $5 \mathrm{ppm}$. It was found that the used lubricant also contained other metals, such as: lead $110 \mathrm{ppm}$, zinc $685 \mathrm{ppm}$, barium $18.1 \mathrm{ppm}$, cadmium $2.5 \mathrm{ppm}$, and chromium $3.2 \mathrm{ppm}$ [38]. Other research had also found increased levels of heavy metals in used lubricant oils compared with in fresh ones [39]. Therefore, used lubricant oil contains a high concentration of heavy metals and may cause a risk to the health of the workers. This arsenic exposure study might indicate that exposure to arsenic could occur particularly to painters and auto mechanics.

\section{CONCLUSION}

An assessment of occupational exposure especially for heavy metal through hair analysis have been carried out. The concentrations of four heavy metal elements, namely lead, chromium, mercury, and arsenic, in the hair of exposed groups were higher than in the control. The differences of those heavy metal concentration in hair compared to the control values indicate the possibility of occupational exposure. Based on the results, lead and chromium were strongly correlated to the occupational exposure due to vehicle emission and paint and oil residues. It can be concluded that hair analysis is a reliable means for assessment of the 
occupational exposure, and that it has some advantages, such as ease of sample collection, transport, storage, and preparation. Thus, the assessment results may be used as references to related institutions in making policies or decisions related to the health of their employees.

\section{ACKNOWLEDGMENT}

The authors would like to acknowledge to Rudi Gunawan, Indri Tristianti, and other colleagues in the health and safety division of PSTNT for their contributions to this research, and PSTNT-BATAN for its financial support for this research.

\section{REFERENCES}

1. T. Zhou, Z. Li, F. Zhang et al., Environ. Toxicol. Pharmacol. 48 (2016) 150.

2. M.I. Szynkowska, M. Marcinek and A. Pawlaczyk, J. Albinska. Environ. Toxicol. Pharmacol. 40 (2015) 402.

3. U.A. Shan and N. Ikram, Int. J. Chem. Biochem. Sci. 1 (2012) 54.

4. R. Kamran, M. Abbas and S. Sarwar, Asian J. Agri. Biol. 2 (2014) 148.

5. S.Q. Abad, P. Rodríguez-González and J.I.G. Alonso, J. Trace Elements Med. Biol. 36 (2016) 16.

6. R. Luo, X. Zhuo and D. Man, Ecotoxicol. Environ. Saf. 104 (2014) 215.

7. M. Huang, X. Chen, D. Shao et al., Ecotoxicol. Environ. Saf. 102 (2014) 84.

8. P. Wołowiec, I. Michalak, K. Chojnacka et al., Clin. Chim. Acta 419 (2013) 139.

9. Y. Pan and H. Li, Environ. Toxicol. Pharmacol. 40 (2015) 678.

10. J.C. Raposo, P. Navarro, A. Sarmiento et al., Microchem. J. 116 (2014) 125.

11. F.I. Abdulrahman, J.C. Akan, M. Chellube et al., World Environment 2 (2012) 81.

12. N. Shaheen, N.M. Irfan, I.N. Khan et al., Chemosphere 152 (2016) 431.

13. H. Ullah, S. Noreen, Fozia et al., Arabian J. Chem. 10 (2017) 10.

14. J.H. Duffus, Pure Appl. Chem.74 (2002) 793.

15. O.O. Peter, I.S. Eneji and R. Sha'Ato, Am. J. Anal. Chem. 3 (2012) 770.
16. MT. Ponzetta, S. Nardi, I. Calliari et al., Biol. Trace Elem. Res. 62 (1998) 199.

17. SC. Foo and TC. Tan, Sci. Total Environ. 209 (1998) 185.

18. W.A. Saputri, F. Tabri, N.N. Waspodo et al., Am. J. Clin. Exp. Med. 4 (2016) 98.

19. E. Damastuti, M. Santoso, DD. Lestiani et al., Characterization of Elements in Human Hair of DLLAJR Officers as a Preliminary Study of Occupational Exposure, Proceeding of Nuclear Analytical Techniques National Seminar (2011) 1. (in Indonesia)

20. H. Kumakli, A.V. Duncan, K. McDaniel et al., Chemosphere 174 (2017) 708.

21. R. Mehra and A.S. Thakur, Arabian J. Chem. 9 (2016) S1214.

22. I. Mollina-Villalba, M. Lacasaña, M. Rodrìguez-Barranco et al., Chemosphere 124 (2015) 83.

23. E.J. Drobyshev, N.D. Solovyev, N.B. Ivanenko et al., J. Trace Elements Med. Biol. 39 (2017) 14.

24. P. Avino, G. Capannesi, L. Renzi et al., Ecotoxicol. Environ. Saf. 92 (2013) 206.

25. Z.D. Brázdová, J. Pomerleau, J. Fiala et al., Cent. Eur. J. Public. Health 22 (2014) 273.

26. Y.S. Hong, Y.M. Kim and K.E. Lee, J. Prev. Med. Public Health 45 (2012) 353.

27. O. Awodele, T.D. Popoola, B.S. Ogbudu et al., Safety and Health at Work 5 (2014) 106.

28. A. Peña - Fernández, M.C. Lobo - Bedmar, M.J. González - Muñoz, Environ. Int. 72 (2014) 170.

29. D. Hong, S.H. Cho, S.J. Park et al., Environ. Toxicol. Pharmacol. 36 (2013) 103

30. G. Giangrosso, G. Cammilleri, A. Macaluso et al., Bioinorg. Chem. Appl. 2016 (2016) 1 DOI:10.1155/2016/5408014.

31. D. Shao, Y. Kang, Z. Cheng et al., Food Chem. 136 (2013) 682.

32. A. Castaño, F. Cutanda, M. Esteban et al., Environ. Res. 141 (2015) 58.

33. V.V.S. Ramakhrisna, V. Singh, A.N Garg, Sci. Total Environ. 192 (1996) 259.

34. D.T. Ogundele, A.A. Adio and O.E. Oludele, J. Environ. Anal. Toxicol. 5 (2015) 1.

35. Y.L. Yu, Y.T. Zhuang, X.Y, Song et al., Chem. Eng. J. 280 (2015) 58. 
36. K. Byun, Y.L. Won, Y.I. Hwang et al., Ann. Occup. Environ. Med. 25 (2013) 21.

37. S.L. Huang, C.Y. Yin and S.Y. Yap, J. Hazard. Mater. 174 (2010) 839.

38. F.I. Karachi, High Metal Content of Used
Motor Oil Poses Hazard to Public Health. http://news.dawn.com. Arsen in lubricant oils Retrieved in March (2009).

39. M.S. Al-Nozili, F.A. Abeed and M.M. Ahmed, Int. J. Emerging Technol. Adv. Eng. 4 (2014) 396. 